\title{
Research on Construction Technology of Emergency Toilets in Japanese Refuge Sites under the Background of Aging
}

\author{
Chenhong Xia ${ }^{1,2}$, Wei Wang ${ }^{1,2}$, Xiaodong Guo ${ }^{1,2}$, Yijie $\mathrm{Li}^{1,2}$ \\ 1. College of Architecture and Urban Planning, Beijing University of Technology, Beijing 100124, China \\ 2. Institute of Earthquake Resistance and Disaster Reduction, Beijing University of Technology, Beijing 100124, China \\ ieeww@bjut.edu.cn
}

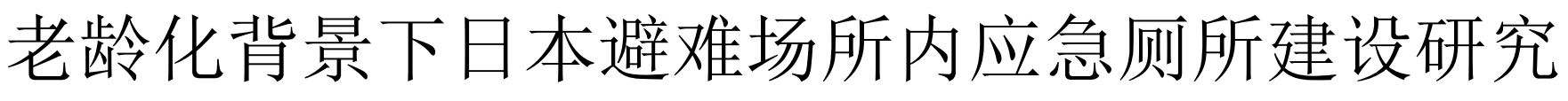

\author{
夏陈红 ${ }^{1,2}$, 王威 ${ }^{1,2}$, 郭晓东 ${ }^{1,2}$, 李轶杰 ${ }^{1,2}$ \\ 1. 北京工业大学, 建筑与城市规划学院, 北京 100124, 中国 \\ 2. 北京工业大学, 抗震减灾研究所, 北京 100124 , 中国
}

ieeww@bjut.edu.cn

\begin{abstract}
In order to solve the problem of inadequate consideration of the sanitary environment of refuge in the planning of refuge places in China, this paper studies the construction technology of toilets in refuge places in Japan, sorts out its management mechanism and implementation policy, and summarizes its innovative technology and implementation process. As a country with a high aging population, Japan pays special attention to the physical and mental health needs of vulnerable groups when constructing toilet facilities in shelters. Through the construction of a sound health management and maintenance mechanism in shelters, a people-oriented scientific and technological concept and a sound logistics support system, the toilet operation problems in shelters have been continuously improved. This paper hopes to provide some advanced experience for the construction of emergency shelters in an aging society by drawing lessons from the research on the most important facilities and toilets in Japanese shelters.
\end{abstract}

Keywords-Aging; Japan; Planning of shelters; Toilet construction technology

摘要一针对我国在避难场所规划时对避难卫生环境考虑不 足的问题, 对日本避难场所中则所的建设技术进行研究, 梳 理其管理机制和实施方针, 总结其创新技术和实现流程。日 本作为高老龄化国家，在进行避难场所中网所设施建设时尤 其关注弱势群体的生理和精神健康需求, 通过建设健全的避 难场所卫生管理和维护机制、以人为本的科技理念和完善的 后勤支援系统, 使得避难场所内的则所运营问题得到不断改 善。本文希望通过借鉴日本避难场所内最重要的设施则所问 题的研究, 为我国步入老龄化社会的避难应急设施建设提供 一些先进经验。

关键词一老龄化; 日本; 避难场所规划; 应急则所建设

\section{I. 引言}

日本作为灾害高发国和人口老龄化国家，对城市应 急避难设施的建设相当重视, 尤其是对避难场所内的灾 害则所的建设[1 3]。在 2011 年的东日本大地震中, 老 年人占受害者的大多数, 据说残疾人受害者比例与受影
响人口的比例相比翻了一番[4 5]。对于需要特殊考虑的 人群, 例如老年人和残疾人, 由于被迫长期居住在一个 生活环境得不到良好维护的避难所, 时长因为则所不卫 生而感到不愉快, 而且犹豫要不要使用则所, 就会使得 避难者忍耐排泄, 控制水分和食品摄取, 导致避难者中 营养状态的恶化和脱水症状, 并引起静脉血栓栓塞症(经 济舱综合症)等疾病的发生。与此同时, 发灾害发生时, 应急则所并不一定马上送到避难所, 与避难者人数相 比，则所的个数可能会不足，东日本大地震发生数日 内, 各应急避难场所内的则所排泄物堆积如山, 处于恶 劣的卫生状态的地方也不少[6 7]。

对于身体状况不达标的弱势群体, 是在避难所的生 活需要特别考虑的人。具体而言, 老年人, 残疾人, 孕 妇, 婴儿, 病人等需要在避难所生活中需要特别考虑的 人, 这些人群是直接导致避难场所是否能正常运营的关 键, 因此, 研究避难场所内应急则所正常运营的课题是 极其重要的[8 11]。在考虑配设支援水、食物等的同 时, 与 “生命线(电气、自来水、煤气、下水道等)”一 样重要的, 作为受灾者 “支撑生命的社会基础服务”之 一的应急则所, 有必要确保则所内设备的维护、运转的 正常等[12 16]。

本文通过对 2015 年兵库县 “生活质量” 改进研究委 员会提出的 “庇护所则所措施指南” 进行研究[17 18], 希望总结日本关于避难场所内应急则所的建设技术经 验, 为我国老龄化背景下的避难场所内卫生设施建设提 供一些借鉴与思考。

\section{II. 日本避难场所内应急则所建设技术流程}

\section{A. 灾时应急则所设置技术}

为了满足避难需求, 日本对传统的日式则所进行了 改造, 在市町村内, 以净化槽、粪便处理、下水道为主 要运营中心, 以防灾科和保健科为组织机构在平时就讨 论灾时则所使用对策, 把 “向避难者提供清洁的则所环 
境” 作为跨部门信息共享、对应体制, 具体改造过程如 图 1 所示。

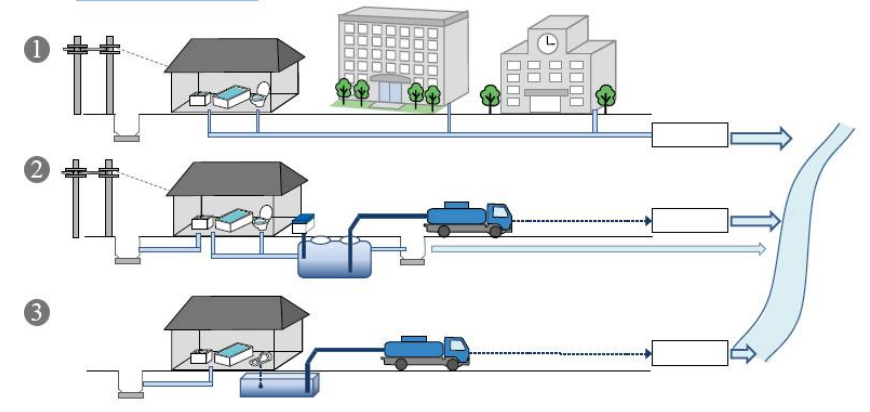

图 1. 避难场所内应急则所运转示意图 Figure1 Map of emergency toilet operation in shelter
由图 1 可知: 步骤 1 中的日式则所存在使用不方 便、运营不高效的缺陷。经过步骤 2 到步骤 3 的改造, 日式则所逐渐转换成西式则所, 不仅能够满足老年人和 残疾人的避难需求，也保障了则所供水、清洁和维护一 体化的运营模式, 即使无供电、无供水也能正常运转, 保障避难环境的卫生。与此同时, 需要相关人员协商如 何判断灾难期间冲水马桶的使用情况及使用方法、使用 规则和注意事项、清洁和维护方法以及保证则所清洁所 需的清洁用品等。

\section{B. 则所配置注意事项}

在则所运营和管理时, 日本在积极采纳残疾人和女 性的意见基础上, 考虑到了则所的设置场所的安全性和 对防盗对策的研究, 确保则所的配置满足各类人群的需 求，总结了应该考虑的事项和应对机制，如表 1 所示。

表 1 . 则所管理时需考虑事项及应对机制

Table 1 Considerations and response mechanisms of the toilet management

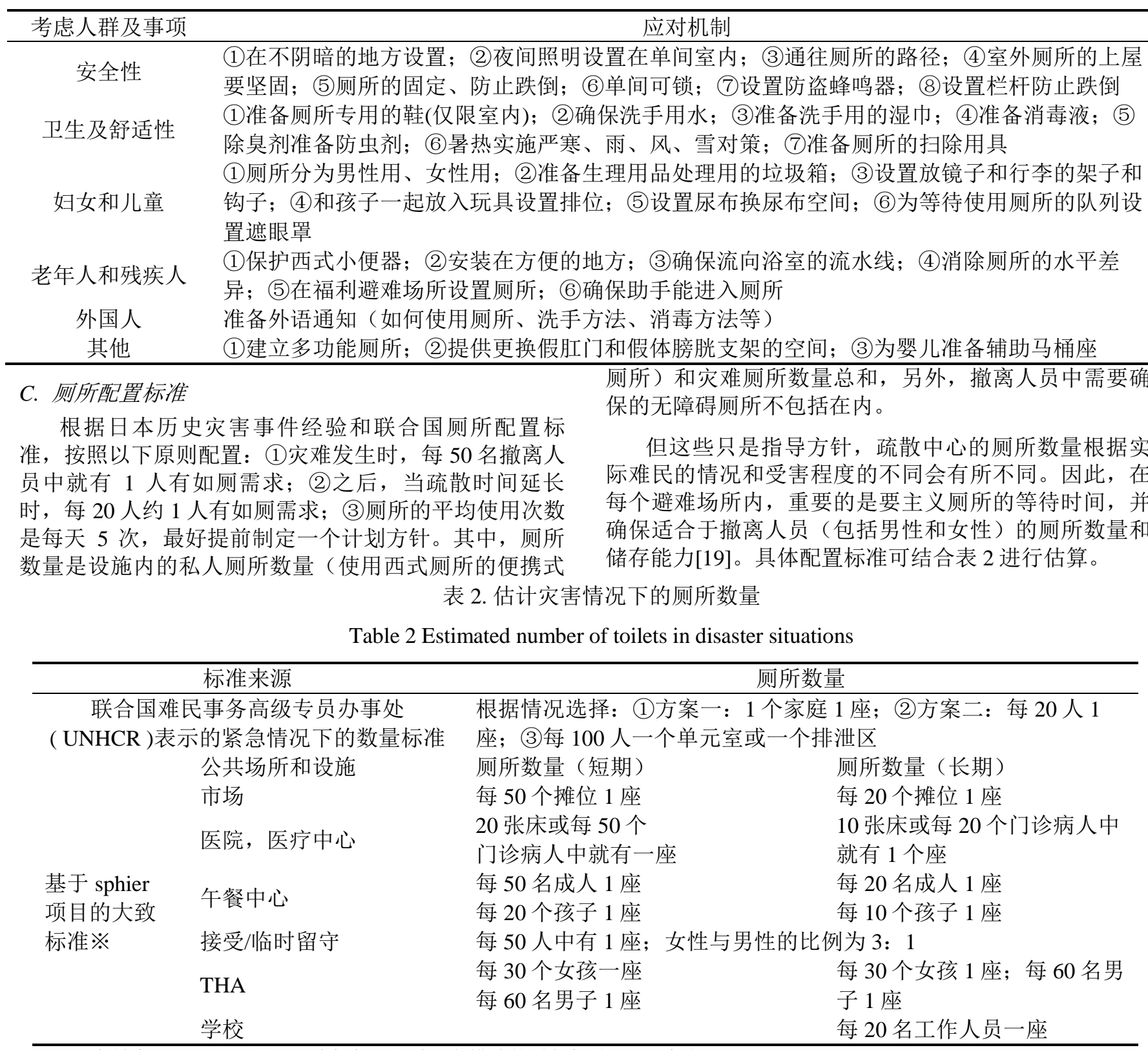

※ (资料来源) Sphere 项目人道宪章和人道主义措施的最低标准 (2011 年版) 


\section{$D$. 则所卫生管理措施}

由于避难所的则所供很多人使用, 因此需要比平时 更注意卫生方面。维持清洁的环境, 可以抑制病毒感染 等二次健康损害, 则所的卫生管理直接关系到避难者的 生命, 所以跟饮用水和食物一样, 应该从避难所开设时 就着手考虑。具体则所卫生管理策略包括: (1)为了让每 个人都能舒适地使用则所, 一个避难场所内的管理系 统, 要能够充分发挥女性同胞的领导能力; (2)为了预防 感染症, 要确保有足够的洗手水; (3)体育馆等室内的则 所要准备专用的鞋子; (4)使用便袋时, 要彻底遵循污秽 物处理的方法, 并确保污秽物的安放地点; (5)最好尽可 能地选择不会被雨水淋湿的地方; (6)如果出现感染症患
者, 也要考虑设立专门的则所; (7)在避难者中, 安排则 所的负责人和打扫值日人员; 8)借助志愿者等支援者的 力量, 维持卫生的则所环境; (9)对卫生管理所需的设备 进行标识。

为了使在灾害时能够考虑到卫生方面的持续清扫、 迅速确定出最低限度的必备品等, 在平时就应当储备 好, 同时, 对于则所使用方法、洗手方法、清扫方法等 的示例, 也需要预先准备好。

表 3 为日本避难场所中必要备用品的例子 [20], 其 中 (表示应该优先准备的物品, o表示需要准备物品。

\section{表 3. 应急策略内必备物品类别}

Table 3 Types of essential items in the emergency strategy

\begin{tabular}{|c|c|}
\hline 分类 & 准备物品 \\
\hline 必需品 & $\begin{array}{l}\text { @卫生纸（首选乙烯基包装）; @生理卫浴产品; @纸质分拣盒/卫生箱（如果是纸板制 } \\
\text { 成, 则需要采取保护措施以防止水从地板表面流出） }\end{array}$ \\
\hline 健康 & $\begin{array}{l}\text { ○手洗水和肥㿝（如果有洗手水）；@湿纸巾（不用手洗）；@手部消毒酒精（不用手 } \\
\text { 洗）； ○纸巾（手洗） }\end{array}$ \\
\hline 清洁人员专用 & @橡胶手套 (一次性); ○口罩(一次性); 恻所清洁工作服 \\
\hline & 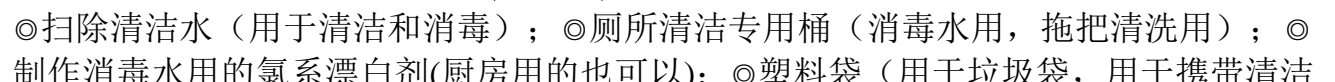 \\
\hline 使用场所) & 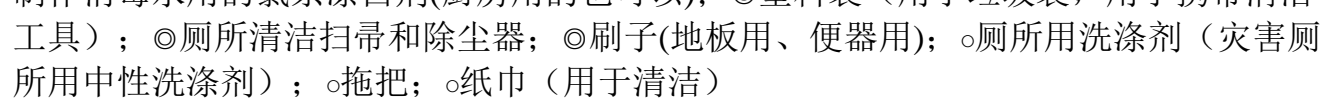 \\
\hline 则所相关备用品等 & 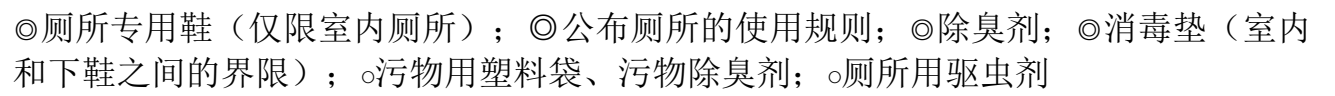 \\
\hline & $\begin{array}{l}\text { 的天数、使用者的情况、避难所的设施条件等进 } \\
\text { 置。日本按照不同的避难需求设置的了对应的处 }\end{array}$ \\
\hline
\end{tabular}

\section{A．卫生间类型配置对策} 施, 如表 4 所示。

如何配置受灾时避难所的则所, 除了根据生命线的 状况和避难场所位置以外, 还需根据灾害发生后需避难

表 4. 则所的组合类型(发生大规模地震时避难所的情况)

Table 4 Types of toilet combination(shelter in the event of a massive earthquake)

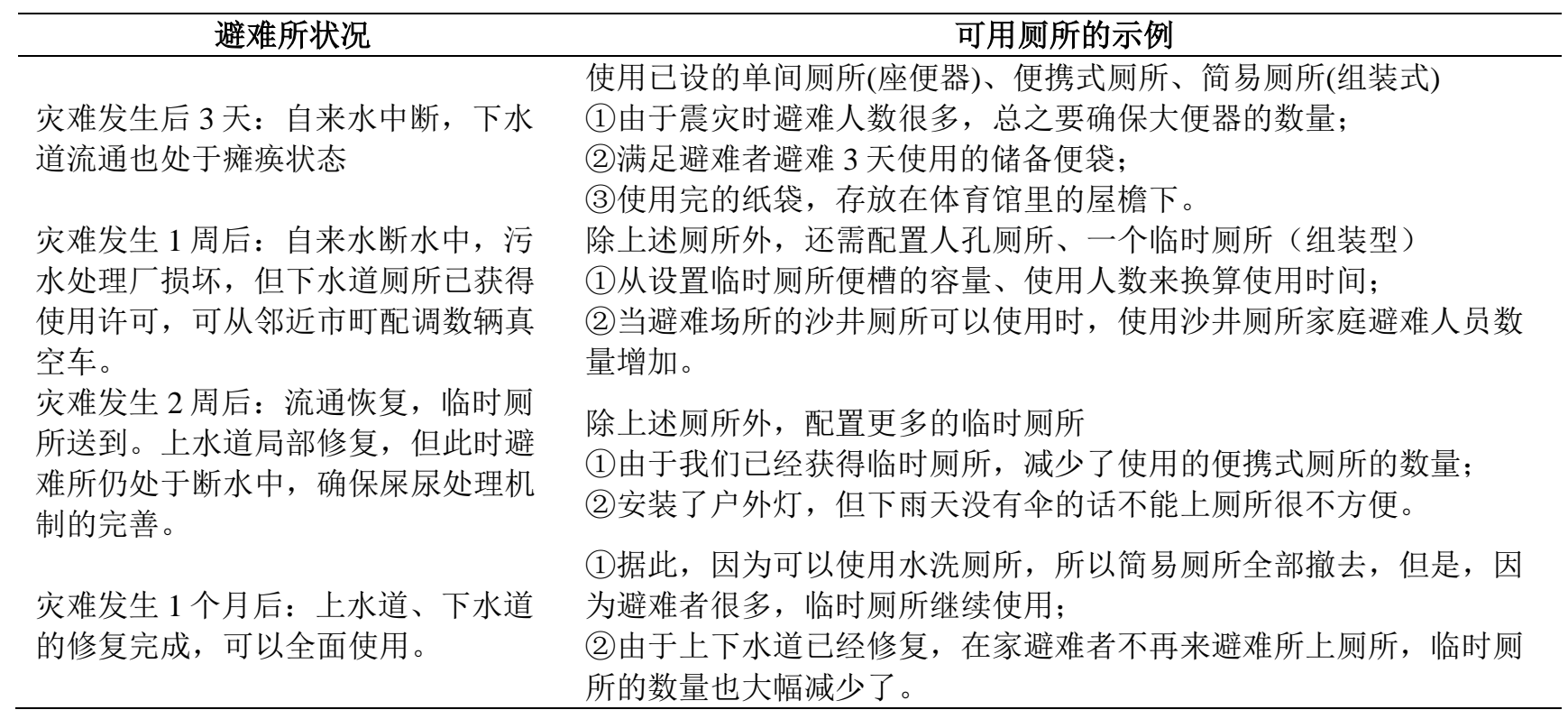


便携式则所、简易则所、临时则所、人孔则所以及

[20]。各类灾害的则所配置情况，如表 5 所示。 在灾害时使用的其他则所将在下文中称为 “灾难则所”

表 5. 随时间推移则所组合类型的变化

Table 5 Changes of toilet combination types over time

\begin{tabular}{ccccc}
\hline 灾害则所的类型 & 灾难约为 3 天 & 灾难约为 2 周 & 灾难约为 1 个月 & 灾难大于等于 3 个月 \\
\hline 便携式则所 & $\star$ & $\circ$ & $\circ$ & \\
简单的则所 & $\star$ & $\circ$ & $\circ$ & $\star$ \\
临时则所 (组装式 & $\circ$ & $\star$ & $\star$ & $\star$ \\
临时则所 & & $\star$ & $\star$ & $\star$ \\
人孔则所 & $\circ$ & $\circ$ & $\circ$ & $\circ$ \\
汽车则所 & & $\circ$ & $\circ$ & $\circ$ \\
自助式则所 & & & &
\end{tabular}

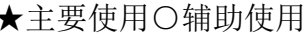

\section{B. 制定灾时厕所安全管理计划}

根据每个疏散中心的损坏情况假设, 选择灾害则 所。在灾害发生前制定 “灾时则所安全管理计划” , 并 结合库存和配送情况等, 确保所需的则所数量, 可参考 “灾时则所的必要数量计算表” 进行换算, 具体用法如 下。

a) 避难场所被破损坏情况假定

- 假设的灾难类型：选择每个避难所预期的灾难类 型，如果预计会发生多种灾难，按照灾难的破 坏性严重程度进行考虑。

- Lifeline 伤害假设: 上水道和污水处理设施功能 中断的天数, 以某一方较长时间不能使用水洗 则所的天数进行假设。(1)上水道功能中断日数 假设, 如果不能使用供水, 则不能使用抽水马 桶, 向水道管理部门确认每次灾害所设想的功 能中断天数; (2)污水处理设施功能性故障天数 假设, 污水处理设施有两种主要类型, 一个是 集体处理类型如污水和社区排水集合处理型, 另一个是合并化粪池和单个化粪池的单独处理 型。确认使用哪种方法后，检查每个负责部门 每次灾难预期的功能故障天数, 并输入天数。

(3)确认最大避难人数, 按照设想的灾害种类和 受灾情况来填写。(4)灾害发生时使用抽水马桶 的规则，具体假设具体设想地震、海啸、大 雨、涨潮导致的浸水、砂土灾害发生时会导致 怎样的破坏，预先制定避难场所的水洗则所使 用规则。

b) 灾害时则所数量的设定

灾时则所数量的保障, 通过活用已设则所的西式便 器, 可以保证数量, 因为在租赁等临时则所到达避难所 之前, 根据道路状况等也可能需要实践, 所以只要有西 式便器和简易便器以及便携式便器的储备能够有效保障 避难人群的需求。

- 目标则所数量: 目标则所数量 $=$ 最大设想避难人 数（a） $\div 50$ 。从过去的灾害和国际标准等来 看, 每 50 名避难者就需要一个便器, 且则所使 用无需长时间排队, 以达到确保受灾者健康的 目的。另外，据统计女性与男性则所的比例为 $3: 1$ 是理想的。
- 现有则所中的西式则所数量: 事先检测避难场 所内可以向避难者开放的西式便器数量, 但是 灾害时这个便器不一定能全部使用, 所以在发 生灾害之后, 应当检查个人房间、便器等是有 损坏情况。

- 现有则所的无障碍则所数量: 残疾人和老年人 在避难所使用的则所需要与一般则所分开设 置, 因此需提前确认各避难所的则所状况, 同 时, 还需在灾害发生后努力确保弱势群体的如 则安全。

- 估算每种则所需配置的数量: 需配置的数量 $=1$ 个西式则所的目标数量 -2 个现有则所的西式 则所的数量。综合考虑储备和流通库存的数 量, 来探讨需补充的便器数量。由于难以全部 用储备来满足, 因此根据发生后避难者的需求 来确定需配置的量也是相当很重要。

上述计算中只使用西式便器的数量, 这是因为有了 便携式则所就能使用, 老年人等脚不好的人和幼儿等都 容易使用。倘若在日式小便器的情况下, 可以通过用板 等密封小便器并准备由纸板等制成的简单则所 (组装 型）来使用。

\section{IV. 日本避难场所内应急则所建设经验总结}

\section{A. 健全的避难场所卫生管理和维护机制}

则所的问题不仅会导致卫生环境的恶化，更会给避 难者带来很多健康损害, 如激增避难者的不愉快感和个 人尊严。因此, 日本在规划建设避难场所时认识到了这 一问题, 并加以重视和认真贯彻落实, 从日常的维护和 技术投入，到灾时的清洁与维护，有效满足了避难者的 现实需求。考虑到发生灾害后, 水洗则所失灵会导致的 避难者心情的变化而导致的生理变化, 从心理学角度设 计和配备则所设施, 有效满足了避难者的避难需求。同 时, 考虑到老龄化背景下老龄人口对日式则所使用不变 的问题, 配备了多种组合理性的则所, 以满足腰腿弱的 老年人和轮椅使用的身体障碍需求。

另外, 考虑到避难人群中会有传染病人员的存在, 为避免受害者自身的感染以及传播给他人, 在避难场所 内不仅配置了专用空间或私人房间, 还在每个避难所内 安排了巡逻公共卫生护士, 以防止感染疾病的发生和恶 化。通过实时对避难场所内整体人群的健康评估和监 
测, 联动疏散行动相关人员、福利领域的专家以及志愿 者等外部支援团体合作，及时解决难民的健康问题，以 改善住所的卫生环境。

\section{B. 完善的组织运营系统和救援支援系统}

市防灾相关局、福利相关部门和卫生相关部门注重 从平时就开始就关注人群避难时则所需求的问题, 特别 是制定需要护理的老年人、残疾儿童、孕妇、婴儿的避 难方案。

关于各避难所的运营系统, 预先决定行政负责人, 其次与市町村中的主要学校、居民协会、自主防灾组织 等的管理者建立日常合作机制, 一旦灾害发生, 能够快 速组建成一个应急系统，保障工作人员自愿聚集在指定 地点, 登记避难场者自身情况和避难需求, 从而及时调 配避难则所。

\section{C. 完善的公众参与制度和教育培训机制}

大力开展防灾宣传教育培训。建立了防灾宣传教育 长效机制, 把防灾知识纳入到了国民素质教育体系及中 小学公共安全教育纲要中, 并将其作为市町村各级领导 干部和公务员培训教育的重要内容, 有效保障了防灾科 普宣传的宣传力度，增强了公众自救互救意识。

\section{V. 结语}

日本在进行避难场所内应急则所设置时尤其关注弱 势群体的生理和精神健康, 通过建立健全的日常卫生管 理机制、以人为本的传染病管理措施和完善的后备支援 系统, 有效保障了灾时普通人群和弱势群体的避难需 求。

我国作为世界上老年人最多、增长最快的国家之 一，在避难场所建设中对弱势群体避难需求的问题也十 分关注，但具体的实施内容却很少，因此，在未来的避 免场所建设时，可充分借鉴日本避难场所的人性化设计 理念、管理维护机制和运营运转模式，在充分借助我国 的科技实力和物质实力的基础上，营造出更为和谐及稳 定的避难环境，保障整个城市灾前灾中灾后的高效运 转。

\section{致谢}

本项目受中国地震局重大政策理论与实践问题研究 课题(CEAZY2019JZ14)；中国地震局地震工程与工程振 动重点实验室重点专项(2019EEEVL0501); 国家重点研 发计划课题（2018YFD1100902-1）; 国家自然科学基金 项目(51678017)资助。

\section{参考文献}

[1] 内閣府（防災担当），“震災時のトイレ対策のあり方に関する調 查研究会（（財）日本消防設備安全センター）, 震災時のトイ レ対策一あり方とマニュアルー,1997.

[2] 日本トイレ研究所, “災害時トイレ衛生管理講習会テキスト, 2014

[3] 中央防災会議幹事会, “南海トラフ地震における具体的な応急対 策活動に関する計画,”2015.

[4] 日本トイレ研究所, “東日本大震災 3.11 のトイレ [EB/OL],” 2013.
[5] 李文静, 翟国方, 顾福妹, 陈泽武, “日本福祉型避难场所建设对我国 老龄化背景下避难场所规划建设的启示,”国际城市规划, vol. 34, issue 1, pp. 119-126, 2019.

[6] 内閣府 (防災担当), “北海道胆振いぶり地方中東部を震源とす る地震に係る被害状況等について（平成 31 年 2 月）, ” 1991 。

[7] 内閣府 (原子力防災担当), “平成 29 年度原子力総合防災訓練 実施成果報告書（平成 30 年 3 月）,”2018

[8] 内閣府（防災担当）、“避難所におけるトイレの確保・管理ガイ ドライン (平成 28 年 4 月) , 2016

[9] 大西一嘉, “大災害時の福祉避難所に関する研究 (地震防災分野 一震害と防災特集 ), ”東濃地震科学研究所報告, pp. 69-72, 2010.

[10] 徐柏刚,孙晖, “微环境一一本针对高龄人群的防灾规划的新视 角,”城市建筑, vol. 22, pp.116-118, 2015 .

[11] 日本学術会議学術体制常置委員会, “大学等の研究環境の改善に ついて一研究支援スタッフの活性化と研究施設整備（平成 17 年 6 月）, 2007.

[12] 王港, 曾坚,王强, “日本城镇海啸避难所规划策略研究[J]. 国际城市 规划,”国际城市规划, vol. 32, issue 6, pp. 84-90, 2017.

[13] 唐波,丘飞鹏, 黄嘉颖, “㓞性城市视角下中国应急避难场所研究进 展,,现代城市研究, issue 9, pp. 25-31, 2017.

[14] 许铃琳, “紧急避震疏散场所平灾转换设计研究,”南京工业大学, 2016.

[15] 赖俊彦,李亦纲,杜晓霞,刘传伟,许建华, “新建社区的地震应急避难 规划研究,”震灾防御技术, vol. 10, issue 3, pp. 629-638, 2015 .

[16] 张琬茗, “针对地震灾害的即时性避难设施设计研究, ”津科技大 学, 2015 .

[17] 兵庫県, “避難所管理運営指針 (平成 25 年版),” 2013.

[18] 兵庫県避難所等におけるトイレ対策検討会, “避難所等における トイレ対策の手引き,” 2014

[19] 内閣府ホーム, “避難所における災害用トイレについて（モデル ケース) (案), ”2015.

[20] 内閣府ホーム, “男女共同参画の視点に立った社会制度・慣行の 見直し,”2018.

通讯作者: 王威 (1981-), 男, 博士, 副研究员, 主要 从事城市防灾规划、生命线系统抗灾技术研究, E-mail: ieeww@bjut.edu.cn. 